\title{
I nteligência organizacional e competitiva e big data: uma visão sistêmica para a gestão sustentável das organizações
}

\author{
Orandi Mina Falsarella' \\ http:// orcid.org/ 0000-0002-2200-5094

\section{Celeste Sirotheau Corrêa Jannuzzi"} \\ 'Pontifícia Universidade Católica de Campinas, SP, Brasil. \\ Docente no Centro de Economia e Administração. \\ "Pontifícia Universidade Católica de Campinas, SP, Brasil. \\ Docente no Centro de Economia e Administração
}

http:/ / dx.doi.org/ 10.1590/ 1981-5344/ 3497

Atualmente o desenvolvimento sustentável, bem como a vantagem competitiva são assuntos muito estudados e perseguidos pelas organizações. Quando se fala em desenvolvimento sustentável estão implícitas as três dimensões da sustentabilidade, ou seja, a econômica, a social e a ambiental, que, se alcançadas em seu conjunto, podem contribuir para a obtenção de vantagem competitiva. No entanto, como é possível saber e monitorar informações internas e externas, estruturadas e não estruturadas e delas extrair fatos relevantes que mostrem como a organização é reconhecida internamente e pela sociedade nos quesitos econômico, social e ambiental? Responder esse questionamento não é tão simples assim, uma vez que estamos vivenciando um crescente aumento de dados e informações disponíveis atualmente. Assim, o objetivo desse trabalho é apresentar como os conceitos de Inteligência Organizacional e Competitiva e de Big Data, utilizados de modo sistêmico, podem responder esse questionamento e contribuir para a 
gestão sustentável das organizações. Em seu desenvolvimento são apresentados, descritos e exemplificados figura e quadros dispostos com etapas, atividades e ações que atendem o objetivo proposto. Os resultados permitiram que a empresa revisse seu Plano Estratégico Empresarial equilibrando suas ações para uma gestão sustentável.

Palavras-chaves: Inteligência Organizacional e Competitiva; Big Data; Gestão Sustentável.

\section{Organizational and competitive intelligence and big data: a systemic vision for the organizations'sustainable management}

Currently, sustainable development as well as competitive advantage are subjects that are largely studied and pursued by organizations. When it comes to sustainable development, the three sustainability dimensions, i.e.economic, social and environmental, which, if achieved as a whole, can contribute to the attainmentof a competitive advantage, are implicit. However, how is it possible to know and monitor internal and external information, structured and unstructured and extract relevant facts that show how the organization is recognized internally and by society in the economic, social and environmental aspects? Answering this questioning is not as simple as we are experiencing a growing increase in data and information currently available. Thus, the objective of this work is to show how the Organizational and Competitive Intelligence concepts and Big Data ones, used in a systemic way, can answer this questioning and contribute to the organizations' sustainable management. In its development, figure and pictures are presented, described and exemplified arranged with steps, activities and actions to reach the proposed objective. The results allowed the company to review its Strategic Business Plan, balancing its actions for sustainable management. 
Keywords: Organizational and Competitive Intelligence; Big Data; Sustainable Management.

Recebido em 29.03.2018 Aceito em 09.09.2018

\section{I ntrodução}

Atualmente, o termo sustentabilidade vem sendo discutido em vários níveis e contextos. Destacam-se os eventos que envolvem a participação de muitos países onde são apresentados os problemas que o aquecimento global pode trazer para a humanidade.

Nos embates ocorridos nas reuniões de Estocolmo (1972) e Rio (1992), nasce a noção de que o desenvolvimento tem, além de um cerceamento ambiental,uma dimensão social. Nessa, está contida a ideia de que a pobreza é provocadorade agressões ambientais e, por isso, a sustentabilidade deve contemplar aequidade social e a qualidade de vida dessa geração e das próximas. A solidariedadecom as próximas gerações introduz, de forma transversal, a dimensão ética. (NASCIMENTO, 2012, p.51).

Não obstante e também afeita a esse tema, as empresas tem-se mostrado muito preocupadas por serem, de certa maneira, responsáveis diretas pelas consequências que as mudanças climáticas podem causar.

Segundo Barbiere et al. (2010), a adesão das empresas ao contexto do desenvolvimento sustentável, tem papel importante para procurar, de alguma forma, tentar diminuir a responsabilidade das instituições pela degradação social e ambiental que está atingindo o planeta.

Associado a isso, percebe-se que é possível essa temática ser utilizada como forma de diferenciação, aumentando o fator competitivo perante a concorrência atualmente existente no mercado, desde que fique evidente para a sociedade que uma determinada empresa seja comprovadamente reconhecida pela sociedade como sustentável.

Para Barbiere et al. (2010), as empresas devem se preocupar com as três dimensões da sustentabilidade. São elas:

- Social - envolve os impactos sociais causados dentro e fora da organização, como por exemplo, desemprego, exclusão social, entre outros;

-Ambiental - diz respeito aos impactos ambientais decorrentes do uso de recursos naturais e emissão de poluentes;

-Econômica - envolve a eficiência econômica, diretamente relacionada à sobrevivência da organização. 
Munck e Souza (2009) complementam a descrição das três dimensões no contexto empresarial quando dizem que a:

- Sustentabilidade Econômica busca vantagem competitiva, melhoria de qualidade, diminuição de custo e possui foco no mercado;

- Sustentabilidade Ambiental se preocupa com o uso de tecnologias limpas, reciclagem, utilização sustentável de recursos naturais, atendimento à legislação e tratamento de efluentes e resíduos, buscando oferecer produtos ecologicamente corretos sem, ou com o mínimo, impacto ambiental;

- Sustentabilidade Social se preocupa com a responsabilidade social, o suporte ao crescimento da comunidade, o compromisso com o desenvolvimento dos recursos humanos e a promoção e a participação da empresa em projetos de cunho social.

Segundo Martins et al. (2010),

em relação ao tripé proposto para o desenvolvimento sustentável, o aspecto ambiental, juntamente com o social, tem sido encarado como um desafio, visto que os objetivos econômicos normalmente prevalecem. (MARTINS et al., 2010, p. 462)

Desses relatos, algumas colocações são interessantes, podendo ser destacado que se para uma empresa a sustentabilidade econômica é fundamental para a sua sobrevivência, as sustentabilidades ambiental e social, também podem, se conseguidase comprovadas, serem fatores competitivos. Além disso, outro ponto importante a ser considerado é que alcançar a sustentabilidade ambiental e a social pode contribuir e ajudar a conseguire ampliara sustentabilidade econômica.

Assim, as três dimensões consideradas fundamentais no contexto da sustentabilidade, se fundem, pois, organização sustentável deve simultaneamente respeitar o meio ambiente, ser eficiente economicamente e lidar adequadamente com a justiça social (Barbiere, 2007), tendo, obviamente para isso, que realizar ações eficientes que busquem justificar e ampliar essa relação.

Um questionamento que pode ser feito é como saber se uma organização está alcançando o desenvolvimento sustentável? Complementando esse questionamento, como estimular uma empresa a alcançar o desenvolvimento sustentável no contexto das três dimensões da sustentabilidade?

Parece que, conhecer o status quo das três dimensões da sustentabilidade de uma organização é o primeiro passo para posteriormente propor estratégias e ações que estimulem o desenvolvimento sustentável na busca por vantagem competitiva. 
Para conhecer o status quo, parece ser a informação um fator primordial para se obter respostas, uma vez que existem vários atores envolvidos nesse contexto e muitas e distintas fontes de informação, sejam elas, as informações internas ou externas à organização e as informações estruturadas e as não estruturadas.

Para Falsarella et al. (2010), no contexto das organizações empresariaisa informação é interna se produzida no ambiente interno da organização e externa, quando vem de fora desta. Já informações estruturadas são codificadas e sistematizadas dentro de uma estrutura pré-estabelecida, enquanto que as informações não estruturadas não são contextualizadas ou documentadas, segundo a estrutura estabelecida nos sistemas computadorizados de informações.

Informações internas e estruturadas são indispensáveis para analisar e avaliar a sustentabilidade econômica, uma vez que dados sobre faturamento, despesas, lucros, vendas, entre outros, estão disponíveis nos vários Sistemas de Informação (SI) existentes nas organizações. Já a avaliação e análise das sustentabilidades ambiental e social são expressas, na maioria das vezes, por meio de informações externas e não estruturadas e são percepções provenientes de diversos atores em sua maioria externos.

Diante dessa colocação, um terceiro questionamento pode ser feito, ou seja, como monitorar informações internas e externas e estruturadas e não estruturadas e delas extrair fatos relevantes que mostrem como a organização é reconhecida internamente e pela sociedade nos quesitos econômico, social e ambiental?

Borkaret al. (2012) dizem que empresas estão monitorando compras, pesquisando produtos, buscando interações com websites e outras informações para aumentar a eficácia do seu marketing, no sentido de prover serviços aos clientes. Governos e empresas estão rastreando o conteúdo de blogs e tweets para realizar análises de sentimentos. Organizações de saúde pública estão monitorando artigos de notícias, tweets, e web para acompanhar o progresso e tendências de epidemias. Os cientistas sociais estão estudando tweets e redes sociais, para entender como a informação de vários tipos se espalha e como podem ser mais eficazmente utilizadas.

No entanto, outro fato complicador surge no processo de monitoramento que é a grande quantidade de informações disponíveis e crescentes, principalmente as existentes e as que são criadas diariamente por meio das mídias e redes sociais.

Mearian (2011) já indicava que no ano de 20110 sepositórios já armazenavam 1,8 zettabytes ou 1,8 trilhões de gigabytes de dados e que a tendência era de aumento contínuo. Ji et al. (2012) corroboram para esta visão de volume de dados, quando relataram que em 2012 o 
Facebook, fornecia 570 bilhões de páginas Web e armazenava 3 bilhões de novas fotos a cada mês, e ainda administrava 25 bilhões de partes de conteúdo.

Atualmente, diante da crescente disponibilidade de acesso por pessoas físicas e jurídicas aos diversos meios de comunicação e a facilidade de criação e obtenção de informações, não há dúvida que a tendência de aumento contínuo, apontado por Mearian (2011) e Ji et al. (2012), se confirmaram e que o volume de dados e informações disponíveis continuaráse ampliando.

Assim, diante das questões ora apresentadas, diante da importância da informação para saber o status quo de uma empresa em relação às dimensões da sustentabilidade e diante da necessidade de estimular o desenvolvimento sustentável para uma instituição tornar-se mais competitiva, o objetivo desse trabalho é apresentar como os conceitos de Inteligência Organizacional e Competitiva e de Big Data utilizados de modo sistêmico podem contribuir para a gestão sustentável das organizações.

Para o desenvolvimento da discussão proposta, a pesquisa bibliográfica se delineou metodologicamente adequada, pois contribui para um pensamento reflexivo que permite descobrir novos fatos e relações em qualquer área de conhecimento (LAKATOS; MARCONI, 2007). O levantamento bibliográfico envolveu literaturas nacionais e internacionaisdisponíveis em anais e periódicos científicos, onde se recuperou os conceitos sobre Sustentabilidade, Big Data e Inteligência Organizacional e Competitiva.

A partir do que foi recuperado na literatura, o tratamento das informações e a construção da abordagem proposta obedeceram as seguintes orientações: em relação à sustentabilidade, foi dado ênfase ao entendimento conceitual e, principalmente, à identificação das três dimensões da sustentabilidade - a econômica, a social e a ambiental -, destacando como a obtenção de informações estruturadas e não estruturadas e de informações internas e externas, se mensuradas por meio de indicadores, podem contribuir para determinar o status quo nessas dimensões; em relação ao Big Data, foi feita uma descrição sobre como este conceito contribui para obter informações externas e não estruturadas que são as que ocorrem em maior volume e que precisam ser tratadas e analisadas, principalmente quanto à sua veracidade; e, em relação aos conceitos de Inteligência Organizacional e Competitiva (IOC), foi feita uma descrição sistematizada sobre como a IOC contribui, por meio do seu ciclo, para auxiliar a descobrir que informações devem ser monitoradas e diante da análise, após a coleta, como os gestores podem propor estratégias competitivas no contexto da sustentabilidade. Como validação da integração dos conceitos estruturados em uma visão 
sistêmica, a proposta foi aplicada em uma empresa que atua no ramo alimentício, mais especificamente na produção de alimentos para fastfood. Esse procedimento caracterizou metodologicamente o presente trabalho, também, como pesquisa aplicada.

\section{Gestão sustentável das organizações}

Segundo Furtado (2005), o termo “sustentável” significa defensável, suportável, capaz de ser mantido e preservado, se algumas condições forem consideradas. O autor afirma ainda que sustentabilidade é um processocontínuo e de longo prazo que em determinadas condições mantém um sistema estável. Complementa trazendo sua definição de Desenvolvimento Sustentável.

Representa, portanto, a maneira de se buscar a melhoria das condições de bem-estar, com consumo de qualidade - por envolver relações harmônicas, de longuíssimo prazo, para o crescimento e desenvolvimento da comunidade humana, com equidade e garantia da qualidade física e biológica dos sistemas ecológicos, que fornecem e garantem os meios para a sustentabilidade da própria sociedade humana. (FURTADO, 2005, p. 15).

Para Amaral (2003) o Desenvolvimento Sustentável se relaciona a três aspectos descritos na literatura da área conhecidos como "triple bottom line". Eles se constituem nas principais dimensões da sustentabilidade, ou seja, a ambiental, a social e a econômica (Amaral, 2003; Claro et al, 2008).

A sinergia entreesses aspectos permeia a aplicação do conceito de Desenvolvimento Sustentável, ou sustentabilidade, onde quer que ele seja aplicado, tanto em nível governamental, como da sociedade civil ou na seara empresarial (AMARAL, 2003, p. 2).

Araujo et al. (2006) afirmam que para as empresas e também para os pesquisadores, a sustentabilidade social, ambiental e econômica, em seu conjunto, ilustra a importância de uma visão da sustentabilidade mais ampla, pois não trata apenas de aspectos econômicos. O autor relata ainda:

É importante salientar que dentro dos princípios de sustentabilidade, não se podem separar as questões sociais das questões ambientais. Por isso, quando uma organização é ecologicamente sustentável, ela também estará atuando de forma socialmente responsável, de forma a atender os interesses de todos os stakeholders que 
afetam ou são afetados por suas atividades (ARAUJO et al., 2006, p. 10).

Segundo Coral 2002, o grande desafio das organizações é mostrar como ser competitiva e sustentável ao mesmo tempo, uma vez que nos modelos de planejamento apresentados, as questões ambientais e sociais são vistas como despesas que podemencarecer produtos e que contrariam a busca por resultados financeiros, o aumento de fatias de mercado e a sobrevivência perante a concorrência. A autora afirma ainda que se esse diferencial não for percebido pelos clientes, poderá representar queda de competitividade e diminuição da possibilidade de sobreviver no ambiente onde atua.A autora conclui que "sustentabilidade de uma empresa dependerá de sua competitividade, da sua relação com o meio ambiente natural e da sua responsabilidade social."

Borelli e Silva (2014) afirmam que a busca pela sustentabilidade empresarial surge como um novo modelo de gestão, pois possuir projetos de cunho social e ambiental pode trazer vantagem competitiva, agregar valor, aumentar a competitividade e melhorar positivamente a imagem institucional.

Nesse sentido, Amaral (2003) reafirma que

Os três componentes do desenvolvimento sustentável: o ambiental, o econômico e o social, têm começado a ser avaliado pelas empresas que são mais pró-ativas. As empresas modernas não devem somente pensar em cumprir as leis ambientais de um país, estado ou município. Elas devem, na medida do possível, serem pró-ativas e planejarem suas atividades de uma maneira sustentável. De fato, as empresas que se comportam de uma maneira mais sustentável, pensando no seu futuro, têm um desempenho melhor nos seus negócios. (AMARAL, 2003, p. 27).

Furtado (2005) complementa ao afirmar que

Para as empresas com fins lucrativos a sustentabilidadesignifica a qualidade do modelo de gestãopara manter a presença competitiva da organização porlongo prazo, com garantia de acesso a bens e serviços,através da preservação, conservação e reposição derecursos e serviços proporcionados pelo capital econômicoe financeiro, capital natural, capital humano e capital social. (FURTADO, 2005, p. 22). 
Assim, é possível afirmar que sustentabilidade empresarial somente será alcançada quando se têm sucesso no modelo de gestão ao se conseguir o equilíbrio entre as sustentabilidades econômica, social e ambiental, ou seja, as organizações passam a extrair do meio ambiente o mínimo necessário para o seu consumo e se preocupam com questões sociais internas e externas ao local em que atuam. Há investimento nas áreas sociais e ambientais que se revertem em retorno de investimento que pode ser apurado em termos econômicos e financeiros, melhorando a competitividade, trazendo vantagens competitivas e tornando a imagem institucional positivamente sustentável. No entanto, como saber se uma organização conseguiu ou está conseguindo alcançar a sustentabilidade em suas três dimensões?

Para Borelli e Silva (2014), um dos grandes desafios do desenvolvimentosustentável é o de criar instrumentos de mensuração que associem variáveis sobre os fenômenos a que se referem. Segundo Callado (2010), é por meio do uso de indicadores que é possível avaliar se as ações estão sendo eficazes e, portanto, se uma organização está alcançando a sustentabilidade econômica, social e ambiental.

Callado (2010) afirma ainda que os indicadores são importantes por permitir o acompanhamento das principais variáveis de interesse da empresa e por facilitar o planejamento de ações que visem melhorias de desempenho. Assim, toda ação visando melhorar a sustentabilidade deve ser acompanhada de indicadores.

Amaral (2003) propõe a criação de um sistema de indicadores para o desenvolvimento sustentável que considerem variáveis ambientais, econômicas e sociais. Segundo Guimarães (2009), os indicadores apontam a situação atual e a que se deseja alcançar e possibilitam mudanças de comportamento, caso seja necessário. Indicadores de sustentabilidade são instrumentos importantes para acompanhar as ações e avaliar o progresso alcançado para se alcançar o desenvolvimento sustentável (Borelli e Silva, 2014).

Para Saraiva (2010), a utilização de indicadores como ferramenta de gestão se torna base para investimentos e decisão de estratégias empresariais. O autor afirma ainda que entender como eles são concebidos e aplicados em cada processo é conhecer o que se pretende observar, fazendo das informações e conteúdos provenientes dos indicadores algo útil à organização, pois em se tratando de sustentabilidade, se transformam em um grupo de medidas quantitativas que podem ser gerenciadas auxiliando a comunicação e o processo de tomada de decisão.

Bellen (2004) reafirma que as ferramentas de avaliação da sustentabilidade também são úteis para o processo de decisão e, além de serem utilizadas para definição de políticas e possuir a função de auxiliar 
no Planejamento Estratégico Empresarial (PEE), apresentam outras funções interessantes. São elas:

- Função analítica - ao ajudar medir e interpretar os dados, agrupando-os em matrizes ou índices;

- Função de comunicação - ao tornar as pessoas responsáveis pelas decisões familiarizados com conceitos e métodos relativos a sustentabilidade;

- Função de aviso e mobilização - ao auxiliar os gestores em tornar os índices a serem alcançados transparentes a todas as pessoas envolvidas;

- Função de coordenação - ao permitir que um sistema de medidas possa integrar dados de diferentes fontes.

O PEE é um processo que consiste na análise sistemática dos pontos fortes e fracos de uma instituição, e das oportunidades e ameaças do meio ambiente com o intuito de estabelecer objetivos, metas e estratégias que possibilitem um aumento da competitividade empresarial (RIZZO; FALSARELLA, 2006).

Após a análise sistemática dos pontos fortes e fracos e das ameaças e oportunidades, quando da sua elaboração, o PEE define:

-Visão de Futuro, ou seja, como a organização quer ser reconhecida em um determinado período de tempo; alvo;

- Missão, que apresenta sua identidade, área de atuação epúblico

- Objetivos e Metas a serem alcançados;

- Estratégias ou planos de ação que serão utilizados para alcançar os objetivos e metas;

- Indicadores com o propósito de medir a situação atual e mensurar se as estratégias escolhidas estão fazendo com que os objetivos e metas estão sendo atingidos.

Normalmente o PEE se preocupa com resultados econômicos e financeiros, de modo a tornar a organização sustentável nessa dimensão e competitiva perante seus concorrentes.

No entanto, nessa nova abordagem onde as questões ambientais e sociaisse tornam importantes no contexto da competitividade empresarial, a elaboração do PEE também deve apresentar objetivos e metas referentes a essas dimensões, devendo ser possível mensurar, por meio dos indicadores, se uma empresa possui gestão sustentável em todas as dimensões da sustentabilidade.

\section{Big data e inteligência organizacional e competitiva}

Nos últimos anos uma grande quantidade de dados provenientes de muitas fontes como: redes sociais; mídias sociais; chamadas de aparelhos móveis; atividades científicas; sistemas de simulações; experimentos; 
sensores ambientais; entre outros, além de fontes tradicionais, estão disponíveis em volumes significativos (Begoli e Horey, 2012, p. 215).

Segundo Falsarellaet al. (2017),

Diante desse enorme e crescente volume de dados e informações é que se delineia um grande problema: como as organizações podem fazer uma observação constante e contínua de seu ambiente, de modo a diminuir o tempo de latência do processo decisório, face ao grande volume de dados e de informações produzido atualmente? (FALSARELLA, JANNUZZI, SUGAHARA, 2017, p.4)

É nesse contexto que surge na literatura científica e empresarial um novo conceito que recebe a denominação de Big Data. ParaHan (2012), Big Data são os dados que não foram objeto de análise por parte das empresas por não existirem tecnologias capazes de coletá-los e analisálos. O autor complementa que Big Data: “... inclui não somente coleta e análise de informações, mas também a sequência de tomada de decisão." (HAN et al., 2012, p. 810, tradução nossa).

Para Begoli e Horey (2012), Big Data refere-se à

[...] prática de coleta e processamento de grandes conjuntos de dados associados a sistemas e algoritmos usados para analisar esses conjuntos de dados massivos. Juntamente com a descoberta de conhecimento; a movimentação de grande volume de dados oferece muitas oportunidades únicas para as organizações se beneficiarem (em relação a novas ideias de negócios, otimizações etc.) (BEGOLI e HOREY, 2012, p. 215, tradução nossa).

Kaisler et al. (2013), afirma que Big Data é um fenômeno caracterizado por três "Vs": Volume, associado a quantidade de informações existentes; Velocidade, associado ao aumento e modificação constante dos dados e das informações; e Variedade, associado às informações estruturadas e não estruturadas. Beulke (2011) apresenta mais dois "Vs", e associa Veracidade à necessidade de se extrair informações confiáveis e Valor à geração de insights quando da análise das informações.

No entanto, buscar informações verídicas, extrair delas insights em um volume crescente de disponibilidade, na velocidade com que são criadas e modificadas e coletá-las e analisá-las, principalmente as informações não estruturadas, mesmo com o conceito de Big Data, não é tarefa simples, pois exige alguma inteligência para que isso possa ser realizado. 
Segundo Agarwal et al. (2013), para extrair insights de grandes volumes de dados, as informações precisam ser correlacionadas ou harmonizadas para um nível comum de granularidade. Os autores complementam que muitas informações valiosas somente são encontradas quando elas são provenientes de fontes externas e são integradas com as informações internas que residem principalmente em bancos de dados relacionais.

Retomando o primeiro questionamento, como saber se uma instituição está alcançando o desenvolvimento sustentável, ou seja, qual é o seu status quo no contexto das três dimensões da sustentabilidade, percebe-se que pelo volume de informações existentes, internas e externas, estruturadas e não estruturadas, é necessário saber onde elas se encontram e como podem ser obtidas para que sejam previamente selecionadas e posteriormente analisadas.

Não bastasse isso, correlacioná-las em um nível comum de granularidade para posteriormente analisá-las, no sentido de propor ações e estratégias que estimulem o desenvolvimento sustentável visando alcançar vantagem competitiva, parece necessitar de ações inteligentes que não podem ser conseguidassomente por meio de Tecnologias da Informação e Comunicação (TIC), mas coordenadas por pessoas, com o suporte das TIC.

Nesse contexto, Falsarella, Jannuzzi e Sugahara (2014) sugerem um conceito conhecido pelo termo Inteligência Organizacional e Competitiva (IOC), que integra as proposições dos termos Inteligência Organizacional e Inteligência Competitiva.

Falsarella, Jannuzzi e Sugahara (2014) afirmam ainda que:

Diante do que representa e propicia para uma organização, a IOC pode contribuir com o Planejamento Estratégico Empresarial ao monitorar o ambiente interno, analisando forças e fraquezas, e o ambiente externo, avaliando ameaças e oportunidades, quando o PEE está sendo elaborado e também quando ele está sendo executado, permitindo rapidamente mudanças de estratégias, quando necessárias. (FALSARELLA, JANNUZZI, SUGAHARA, 2014, p. 11).

Esse processo pode ser suportado pelas etapas do ciclo da inteligência organizacional e competitiva, conforme descrito por Alves e Falsarella (2009, p. 317-318) e sintetizado a seguir:

- Planejamento - é determinado o campo de interesse que uma organização pretende observar, definida a demanda e as fontes de informação e descrito as necessidades e finalidades. Nessa etapa, procura-se identificar que dados e informações são importantes e podem fornecer subsídios à etapa de análise; 
- Coleta de dados e informações - tem início, após a identificação das fontes de informação, o processo de busca nos locais onde os dados se encontram;

-Análise - procura identificar padrões e tendências significativas, por meio da busca de relações, até então não encontradas entre os dados;

- Disseminação - é essa etapa que se preocupa em entregar a informação tratada e analisada para o usuário final em um formato adequado, de modo que ele possa tomar a decisão mais adequada.

Como afirmado pelos autores, é na etapa de Planejamento que se determina qual é o campo de interesse e que informações importantes merecem ser coletadas e analisadas. É nessa etapa também que são definidos os critérios de análise. É óbvio que essa etapa é desenvolvida por seres humanos.

Uma vez tendo sido descritas que informações deverão ser coletadas na etapa de Planejamento, deve ser estabelecido onde elas se encontram, ou seja, quais sãos as bases de dados internas ou externas que deverão ser consultadas, se as informações são estruturadas ou não estruturadas e deve-se proceder, portanto, a etapa de Coleta de Dados e I nformações.

De posse das informações coletadas, é possível iniciar a etapa de Análise do Ciclo da IOC, entregando a informação tratada e analisada para os requisitantes, encerrando, assim, as etapas do ciclo da IOC.

Portanto, pode-se afirmar que os conceitos de IOC e Big Data são complementares, pois, é nas etapas de Coleta de Dados e de Análise que o conceito de Big Data é útil, pois pode coletar e analisar um conjunto muito grande de dados, principalmente as provenientes de informações externas e não estruturadas, e gerar novos conhecimentos não percebidos, caso o processo coleta e de análise fosse feito exclusivamente por Seres Humanos.

\section{Visão sistêmica da gestão sustentável das organizações}

Retomando os questionamentos iniciais, cujas possíveis respostas podem ser vistas na relação sistêmica entre os conceitos de Big Data (sistemas e algoritmos usados para coletar e selecionar dadoscorrelacionando-os para posterior análise), de Inteligência Organizacional e Competitiva (ciclo da IOC) e de Gestão Sustentável (dimensões social, econômica e ambiental) é apresentada e descrita a Figura 1, composta por seis etapas que representam a integração destes conceitos.

Na etapa 1, Ciclo da IOC, atividade de Planejamento, em primeiro lugar deve ser determinado o campo de interesse que a organização deseja observar. Para isso, deve ser elencado pelas pessoas responsáveis 
pelo desenvolvimento dessa atividade o conjunto de indicadores que podem responder esses questionamentos.

Para relacionar os indicadores, esse trabalho será facilitado caso a organização possua um Planejamento Estratégico Empresarial (PEE), com metas e objetivos definidos. Basta, portanto, verificar junto a cada objetivo/meta quais são os indicadores que serão utilizados para avaliar a performance a ser alcançada. O Quadro 1 representa as atividades e ações dessa etapa.

Figura 1 - Gestão Sustentável das organizações - Big Data e IOC

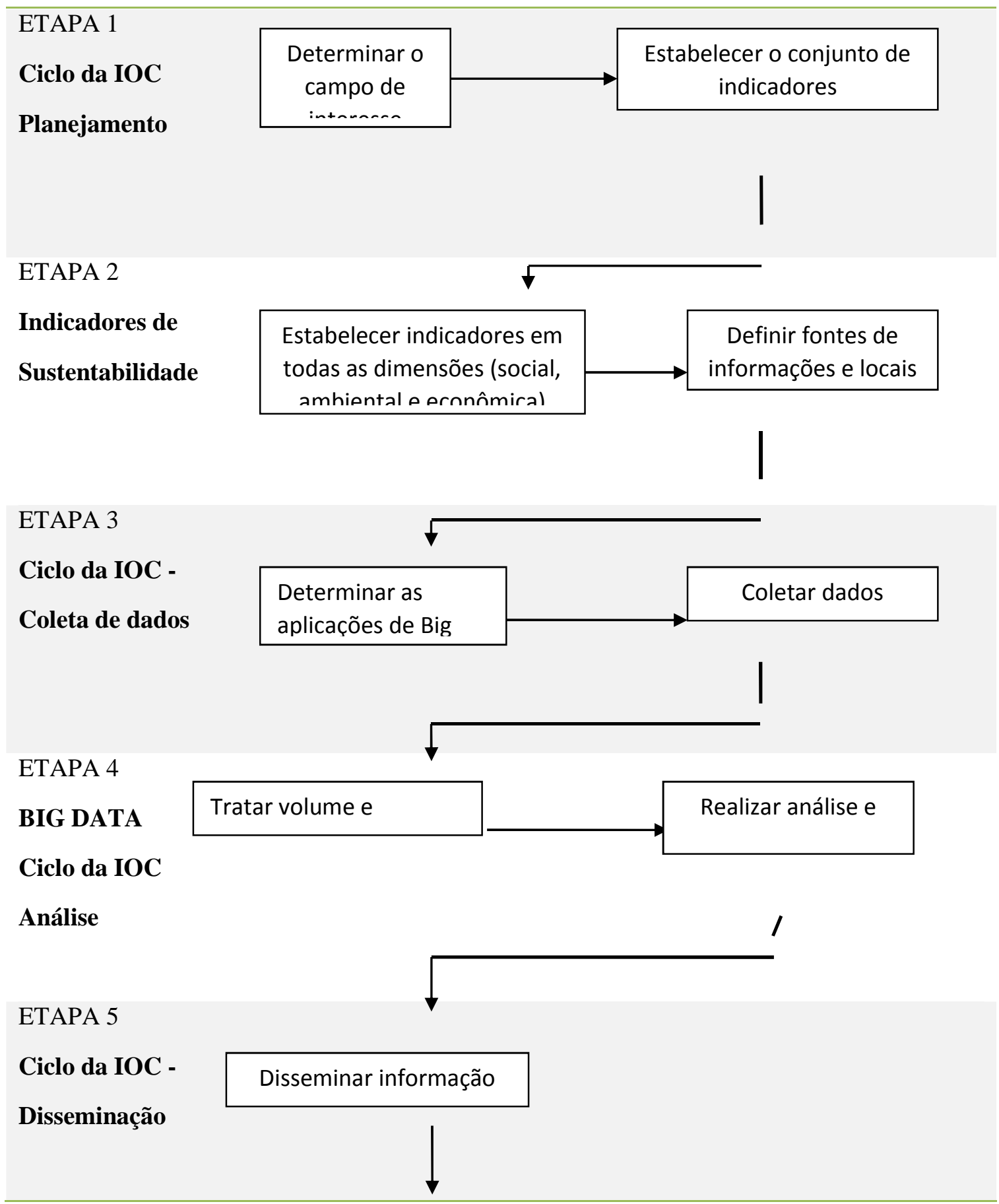




\section{ETAPA 6}

PEE

Objetivos, metas

$$
\begin{gathered}
\text { Analisar e avaliar indicadores } \\
\text { de sustentabilidade }
\end{gathered}
$$

Estabelecer, ou

rever,

e estratégias

\section{Fonte: autores}

Na etapa 2, Indicadores de Sustentabilidade, cada indicador deve ser classificado em uma das dimensões da sustentabilidade, ou seja, econômica, social e ambiental. Nessa classificação algumas fragilidades podem ser encontradas, como por exemplo, a existência de muitos indicadores preocupados em avaliar a dimensão econômica e poucos relacionados às dimensões social e ambiental. Nesse caso, há indícios que o PEE não traduz em seus objetivos e metas preocupação da organização com a gestão sustentável em todas as suas dimensões. Outra fragilidade para obtenção dos indicadores é a ausência do PEE.

A seguir são apresentados exemplos de indicadores em cada uma das dimensões:

1. Econômica - faturamento anual, taxa de lucratividade, despesa líquida, pagamento de salários, pagamento de fornecedores, entre outros;

2. Social - número de empregados que residem na região onde a instituição atua, número de pessoas atendidas por projetos sociais desenvolvidos pela empresa, número de funcionários capacitados anualmente, índice de satisfação social, índice de crescimento educacional, taxa de inclusão social, entre outros;

3. Ambiental - percentual de materiais enviados para reciclagem, percentual de água reciclada, índice de emissões de gases tóxicos, índice de satisfação ambiental, índice de reconhecimento de uso de tecnologias limpas, índice de reconhecimento de atendimento à legislação ambiental, entre outros.

\begin{tabular}{|c|c|}
\hline Etapa 1 - Atividades & Ações \\
\hline $\begin{array}{l}\text { Determinar o campo de } \\
\text { interesse }\end{array}$ & $\begin{array}{l}\text { 1. Determinar o ambiente interno e externo que a } \\
\text { instituição deseja observar, destacando a necessidade e } \\
\text { a finalidade de dados e informações no contexto da } \\
\text { gestão sustentável; }\end{array}$ \\
\hline $\begin{array}{l}\text { Estabelecer o conjunto de } \\
\text { indicadores }\end{array}$ & $\begin{array}{l}\text { 2. Estabelecer um conjunto de indicadores que possam } \\
\text { descrever como a instituição se encontra em relação às } \\
\text { três dimensões da sustentabilidade. }\end{array}$ \\
\hline
\end{tabular}

Quadro 1 - Ciclo da IOC Planejamento - atividades

Fonte: Autores. 
De posse dos indicadores, devem ser definidas as fontes informação, onde elas se encontram, se são estruturadas, não estruturadas, internas ou externas. O Quadro 2representa as atividades e ações dessa etapa.

Quadro 2 - Indicadores de Sustentabilidade - atividades

\begin{tabular}{lrl}
\hline \multicolumn{1}{c}{ Etapa 2 - Atividades } & \multicolumn{1}{c}{ Ações } \\
\hline Classificar indicadores & 3. & $\begin{array}{l}\text { Associar cada indicador a uma das dimensões da } \\
\text { sustentabilidade; }\end{array}$ \\
\hline $\begin{array}{l}\text { Estabelecer indicadores em } \\
\text { todas dimensões }\end{array}$ & 4. & $\begin{array}{l}\text { Verificar se os indicadores dispostos em cada } \\
\text { dimensão são suficientes para avaliar se a instituição } \\
\text { possui gestão sustentável em todas as dimensões; }\end{array}$ \\
\hline $\begin{array}{l}\text { Definir fontes de informações } \\
\text { e locais onde se encontram }\end{array}$ & 5. & $\begin{array}{l}\text { Definir quais são as fontes de informação que } \\
\text { precisam ser consultadas, se elas são estruturadas, não } \\
\end{array}$ \\
& estruturadas, internas ou externas e os locais onde se \\
& encontram; \\
\hline
\end{tabular}

Fonte: Autores.

Na etapa 3 - Ciclo da IOC, atividade de Coleta de Dados, diante dos locais onde as informações se encontram, tem início o processo de busca dos dados que necessitam ser coletados com o propósito de valorar os indicadores.

A etapa 4, BIG Data Ciclo da IOC, atividade de Análise, se inicia junto com a coleta de dados. Nessa etapa, devem ser determinadas as aplicações de BIG Data que serão responsáveis por tratar o volume de dados a serem coletados, a variedade de informações, externas, internas, estruturadas e não estruturadas, a veracidade das informações, ou seja, se podem ou não ser confiáveis e se as mesmas agregam valor ao que se pretende observar, buscando identificar padrões e tendências significativas.

A etapa 4, diante do volume de informações a serem coletadas e das relações a serem analisadas, normalmente é totalmente automatizada, embora possa ter alguma intervenção humana das pessoas responsáveis por esse processo. Um exemplo dessa intervenção humana poderia ser a validação se uma informação é verídica ou não, cujo processo de análise automatizado não tenha conseguido identificar.

Diante dos exemplos de indicadores descritos anteriormente, os mais fáceis de serem valorados são os provenientes de informações internas e estruturadas, como faturamento anual, taxa de lucratividade, despesa líquida, entre outros. Essas informações normalmente estão disponíveis nas bases de dados internas mantidas pela instituição.Já os indicadores índice de satisfação social da empresa medido diante da sociedade, índice de crescimento educacional da comunidade, taxa de inclusão social, índice de satisfação ambiental,índice de reconhecimento do uso de tecnologias limpas e índice de reconhecimento de atendimento 
da legislação ambiental, são provenientesde informações externas e não estruturadas decorrentes, por exemplo, de análises de postagens realizadas por pessoas em mídias e redes sociais.

Nesse ponto, após todo o processo de coleta e análise, é possível valorar os indicadores. Assim, as informações coletadas, tratadas e analisadassãoentregues aos destinatários, finalizado na etapa 5 Ciclo da IOC, atividade de Disseminação, de modo que os gestores possam tomar as decisões mais adequadas. O Quadro 3 representa as atividades e ações das etapas 3, 4 e 5.

Na etapa 6, PEE Objetivos, Metas e Estratégias, os gestores devem analisar os objetivos e metas do PEE e os indicadores associados a cada dimensão da sustentabilidade (econômica, social e ambiental), com o propósito de determinar o status quo em que a organização se encontra em relação à sua preocupação com a gestão sustentável. Nessa análise, quando da elaboração do $\mathrm{PEE}$, deve ser avaliado se há equilíbrio entre os objetivos, metas e indicadores e as dimensões da sustentabilidade - os objetivos podem, por exemplo, estarem associados em sua maioria à dimensão econômica da sustentabilidade, havendo pouca preocupação com a social e a ambiental. Apresentando equilíbrio, ou revendo o PEE para que isso aconteça, realiza-se uma segunda análise para verificar o valor dos indicadores e o quanto eles se encontram distantes das metas a serem alcançadas, podendo, essa análise, dar indícios da necessidade de rever as estratégias.

Quadro 3 - Ciclo de IOC Coleta de Dados, Big Data, Ciclo da IOC Análise e Disseminação - atividades

\begin{tabular}{|c|c|}
\hline Etapas 3, 4 e 5 & Ações \\
\hline $\begin{array}{l}\text { Determinar as aplicações de } \\
\text { Big Data }\end{array}$ & $\begin{array}{l}\text { 6. Escolher as aplicações de Big Data que vão ser } \\
\text { responsáveis por coletar os dados, analisa-los e fazer } \\
\text { relações com o propósito de valorar os indicadores; }\end{array}$ \\
\hline Coletar dados & $\begin{array}{l}\text { 7. Coletar dados nos locais e fontes determinadas na } \\
\text { etapa } 2 \text {; }\end{array}$ \\
\hline Tratar volume e variedade & $\begin{array}{l}\text { 8. Tratar o volume de dados coletados e a variedade de } \\
\text { dados externos, internos, estruturados e não } \\
\text { estruturados; }\end{array}$ \\
\hline Realizar análise & $\begin{array}{l}\text { 9. Avaliar a veracidade das informações, descartando as } \\
\text { não confiáveis, analisar se as mesmas agregam valor e } \\
\text { se é possível identificar padrões e tendências; }\end{array}$ \\
\hline Valorar os indicadores & 10. Valorar os indicadores de sustentabilidade; \\
\hline Disseminar informação & $\begin{array}{l}\text { 11. Disponibilizar os indicadores valorados ás pessoas } \\
\text { responsáveis pelo processo de decisão. }\end{array}$ \\
\hline
\end{tabular}

Fonte: Autores. 
Outra análise é acompanhar a execução do PEE, valorando os indicadores periodicamente para saber se os objetivos e metas distribuídos em todas as dimensões estão sendo alcançados. Diante das análises, o PEE pode ser revisto, estabelecendo novos objetivos e metas visando o equilíbrio entre as três dimensões da sustentabilidade, além do estabelecimento de novas estratégias com o propósito de as metas serem alcançadas.O Quadro 4 representa as atividades e ações dessa etapa.Assim, essas etapas podem ser refeitas várias vezes, inclusive com o estabelecimento de novos indicadores.

Quadro 4 - PEE, Objetivos, metas e estratégias - atividades

\begin{tabular}{lc}
\hline \multicolumn{1}{c}{ Etapa 6 - Atividades } & \multicolumn{1}{c}{ Ações } \\
\hline $\begin{array}{l}\text { Analisar e avaliar indicadores } \\
\text { de sustentabilidade }\end{array}$ & $\begin{array}{l}\text { 12. } \\
\text { Diante dos indicadores valorados, apontar os que são } \\
\text { considerados satisfatórios e os que precisam ser } \\
\text { melhorados; }\end{array}$ \\
\hline $\begin{array}{l}\text { Estabelecer, ou rever, } \\
\text { objetivos e metas }\end{array}$ & $\begin{array}{l}\text { 13. } \\
\text { Rever ou estabelecer novos objetivos e metas no } \\
\text { sentido de alcançar o desenvolvimento sustentável; }\end{array}$ \\
\hline Definir estratégias & $\begin{array}{l}\text { 14. Definir estratégias e planos de ação com vistas a } \\
\text { melhorar os indicadores sustentabilidade em todas } \\
\text { asdimensões da sustentabilidade. }\end{array}$ \\
\hline
\end{tabular}

Fonte: Autores.

\section{Aplicação da visão sistêmica}

As seis etapas que procuramdemonstrar a relação entre os conceitos de Big Data, de Inteligência Organizacional e Competitiva e de Gestão Sustentável na construção de uma visão sistêmica, foram aplicadas junto ao Planejamento Estratégico Empresarial (PEE) de uma empresa do ramo alimentício, que atua na produção de alimentos para fastfood.

Analisando o PEE da empresa, etapa 1,Ciclo da IOC atividade de planejamento, foi possível determinar os indicadores decorrentes dos objetivos e das metas a serem alcançadas pela instituição, conforme descrição no Quadro 5. 
Quadro 5 - Objetivos, metas e indicadores

\begin{tabular}{lll}
\hline \multicolumn{1}{c}{ Objetivos } & Metas & \multicolumn{1}{c}{ Indicadores } \\
\hline Aumentar as vendas & $15 \%$ em 12 meses & Valor faturado \\
\hline $\begin{array}{l}\text { Diminuir o percentual de } \\
\text { perda de matéria prima }\end{array}$ & $80 \%$ em 12 meses & $\begin{array}{l}\text { Percentual de perda de } \\
\text { matéria prima }\end{array}$ \\
\hline $\begin{array}{l}\text { Melhorar o } \\
\text { Planejamentoda produção } \\
\text { diminuir a ociosidade de } \\
\text { pessoal) }\end{array}$ & $20 \%$ em 12 meses & Número de horas ociosas \\
\hline $\begin{array}{l}\text { Diminuir a manutenção } \\
\text { corretiva dos maquinários }\end{array}$ & $80 \%$ em 12 meses & $\begin{array}{l}\text { Número de horas que a linha } \\
\text { de produção fica parada }\end{array}$ \\
\hline $\begin{array}{l}\text { Diminuir os erros de } \\
\text { datação de produção e } \\
\text { validade de produtos }\end{array}$ & $30 \%$ em 6 meses & $\begin{array}{l}\text { Número de erros de datação } \\
\text { de produtos }\end{array}$ \\
\hline $\begin{array}{l}\text { Aumentar a capacitação de } \\
\text { pessoal }\end{array}$ & $20 \%$ em 12 meses & $\begin{array}{l}\text { Número de funcionários } \\
\text { capacitados }\end{array}$ \\
\hline $\begin{array}{l}\text { Melhorar a satisfação } \\
\text { dosclientes }\end{array}$ & $\begin{array}{l}\text { De } 5 \text { para } 9 \text { em } 12 \\
\text { meses }\end{array}$ & $\begin{array}{l}\text { Índice de satisfação dos } \\
\text { clientes }\end{array}$ \\
\hline $\begin{array}{l}\text { Melhorar a comunicação } \\
\text { externa (número de pessoas } \\
\text { que conhecem os produtos) }\end{array}$ & $\begin{array}{l}120 \% \text { em } 12 \\
\text { meses }\end{array}$ & $\begin{array}{l}\text { Número de pessoas que } \\
\text { conhecem os produtos da } \\
\text { empresa }\end{array}$ \\
\hline
\end{tabular}

Fonte: adaptado do PEE empresa

Dando início à etapa 2, Indicadores de sustentabilidade, cada indicador foi vinculado a uma das dimensões da sustentabilidade e foram estabelecidas as fontes e locais ondeas informações se encontram (vide Quadro 6). 
Quadro 6 - Dimensões da Sustentabilidade x Indicadores

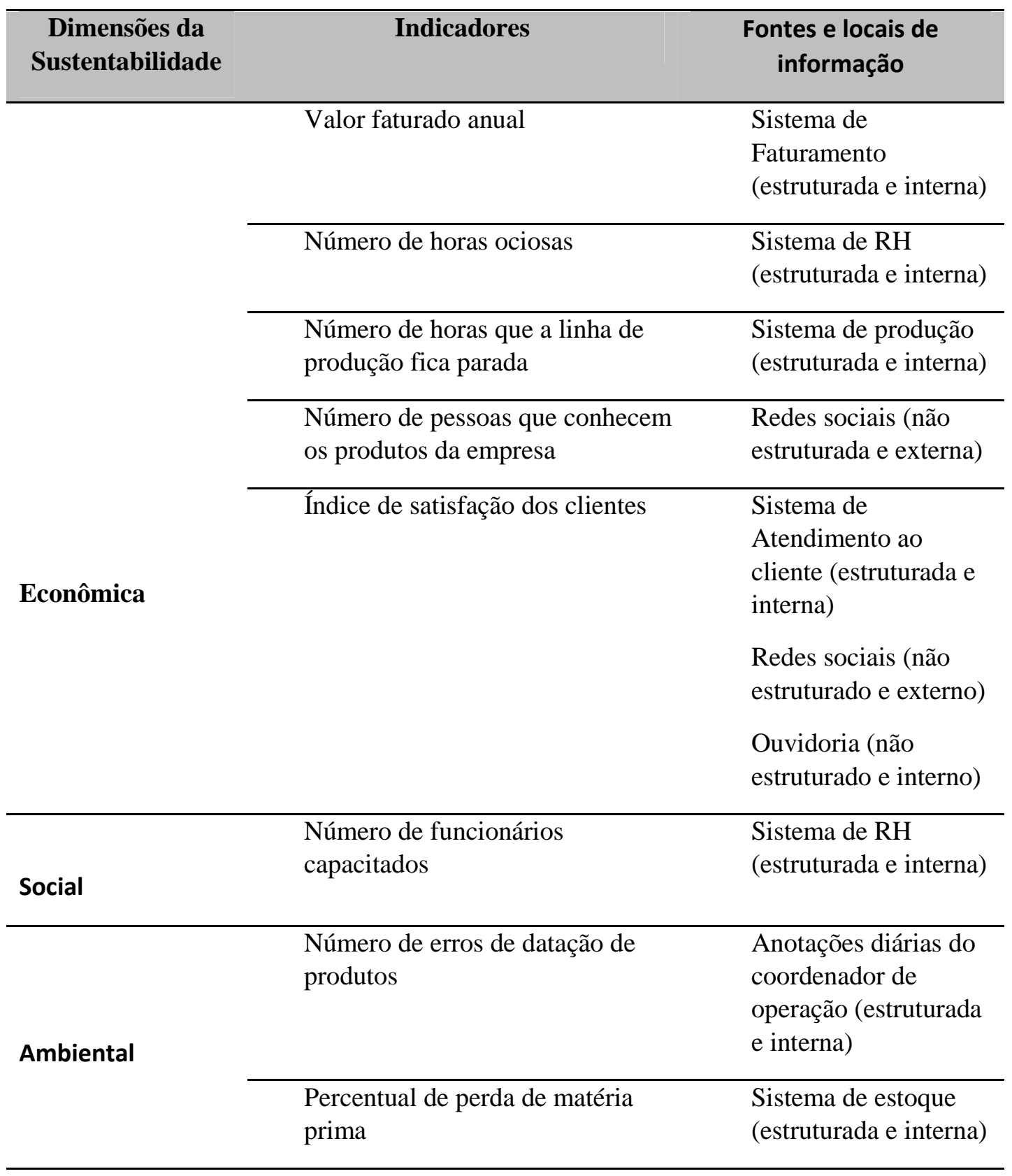

Fonte: Autores

Tendo os indicadores, inicia-se a etapa 3, Ciclo da IOC, atividade de Coleta de Dados concomitante com a etapa 4, Ciclo da IOC, atividade de análise. Para valorar os indicadores valor faturado, número de horas ociosas, número de horas que a linha de produção fica parada, número de funcionários capacitados, número de erros de datação de produtos e percentual de perda de matéria prima, que são informações internas e estruturadas, os próprios sistemas internos - automatizados ou não -, uma vez consultados, fornecem essas informações sem necessidade de análises mais sofisticadas (vide o Quadro 7). 
Quadro 7 - Valoração dos indicadores informações internas e estruturadas

\begin{tabular}{lll}
\multicolumn{1}{c}{ Indicadores } & \multicolumn{1}{c}{ Valor } & Meio de Valoração \\
\hline Valor faturado anual & $\mathrm{R} \$ 153.025 .323,25$ & $\begin{array}{l}\text { Somatório do } \\
\text { faturamento mensal }\end{array}$ \\
\hline $\begin{array}{l}\text { Número de horas } \\
\text { ociosas }\end{array}$ & 3.250 & $\begin{array}{l}\text { Somatório das horas } \\
\text { ociosas diárias de } \\
\text { todos os funcionários } \\
\text { da linha de produção }\end{array}$ \\
\hline $\begin{array}{l}\text { Número de horas que a } \\
\text { linha de produção fica } \\
\text { parada }\end{array}$ & 960 & $\begin{array}{l}\text { Somatório das horas } \\
\text { diárias que as } \\
\text { maquinas ficam } \\
\text { paradas }\end{array}$ \\
\hline $\begin{array}{l}\text { Número de } \\
\text { funcionários } \\
\text { capacitados }\end{array}$ & & $\begin{array}{l}\text { Somatório do número } \\
\text { de funcionários } \\
\text { capacitados }\end{array}$ \\
\hline $\begin{array}{l}\text { Número de erros de } \\
\text { datação de produtos }\end{array}$ & 150 & $\begin{array}{l}\text { Somatório das } \\
\text { anotações diárias }\end{array}$ \\
\hline $\begin{array}{l}\text { Percentual de perda de } \\
\text { matéria prima }\end{array}$ & 15 & $\begin{array}{l}\text { Somatório (matéria } \\
\text { prima adicional/ } \\
\text { matéria prima inicial)* } \\
100\end{array}$ \\
& 225 &
\end{tabular}

Fonte: Autores

Quanto ao indicador, assinalado comonúmero de pessoas que conhecem os produtos da empresa, pela ausência de Big Datafoi feito um levantamento no Facebook, com o propósito de saber, pelo menos de forma inicial, uma amostragem da quantidade de pessoas que mencionam produtos que a empresa comercializa, a quantidade de curtidas e o número de pessoas que receberam compartilhamentos de produtos (vide Quadro 8). Quanto ao índice de satisfação dos clientes, foram realizadas duas análises, uma por meio do sistema de atendimento ao cliente, inserindo a avaliação do atendimento por parte do cliente e o sentimento do atendente quanto ao contato, ou seja, se foi uma reclamação ou elogio por parte do cliente, bem como nos e-mails enviados para a ouvidoria (vide Quadro 8). 
Quadro 8 - Valoração dos indicadores informações externas e não estruturadas

\begin{tabular}{lll}
\multicolumn{1}{c}{ Indicadores } & Valor & \multicolumn{2}{c}{ Meio de Valoração } \\
\hline $\begin{array}{l}\text { Número de pessoas } \\
\text { que conhecem os } \\
\text { produtos da } \\
\text { empresa }\end{array}$ & 1.523 & $\begin{array}{l}\text { Quantidade de pessoas que } \\
\text { mencionam os produtos, acrescidos } \\
\text { do número de pessoas } \\
\text { compartilhadas e quantidade de } \\
\text { curtidas }\end{array}$ \\
\hline $\begin{array}{l}\text { Índice de satisfação } \\
\text { dos clientes }\end{array}$ & 5 & $\begin{array}{l}\text { Relação (número de avaliações } \\
\text { positivas / total de avaliações) * } 10\end{array}$
\end{tabular}

Fonte: Autores

Finalizada a valoração dos indicadores, a informação tratada e analisada foi entregue aos gestores - etapa 5, Ciclo da IOC Disseminação - e iniciou-se a Etapa 6, PEE objetivos e metas.

Nesse momento resgatou-se o Quadro 6 - Dimensões da Sustentabilidade $x$ Indicadores, e ficou evidente que a grande preocupação da empresa é com a sustentabilidade econômica, visto a quantidade de indicadores associados a essa dimensão. Nesse caso, se a empresa desejar buscar a gestão sustentável, deverá rever o PEE inserindo objetivos que possam, por exemplo, ampliar o número de empregados que residem na região onde ela atua, ampliar o número de projetos sociais para a comunidade, se preocupar com a reciclagem de material e com o tratamento da água utilizada no processo de produção dos alimentos, equilibrando assim a preocupação com a sustentabilidade em todas as suas dimensões.

Analisando os quadros 6,7 e 8, nos objetivos que possuem indicadores cujo crescimento ou diminuição são maiores que 50 \%, notase que o percentual de perda de matéria prima deve passar de $15 \%$ para 3\%, o número de horas de máquinas paradas decorrentes de manutenção corretivas deve passar de 960 para 192, o número de pessoas que conhecem os produtos da empresa deve aumentar de 1.500 para 3.300 e o índice de satisfação do cliente deve passar de 5 para 9 em uma escala de zero a dez. Diante dessa análise, as estratégias devem ser avaliadas, pois se as metas não forem alcançadas a gestão sustentável também não se concretizará. Por fim, é necessário acompanhar a execução do PEE, valorando os indicadores periodicamente para saber se os objetivos e metas distribuídos em todas as dimensões estão sendo alcançados. 


\section{Considerações finais}

Pode se afirmar que uma empresa possui preocupação com a gestão sustentável quando ela está monitorando por meio de indicadores o ambiente onde atua nas três dimensões da sustentabilidade, entende que a sustentabilidade social e a ambiental pode trazer vantagem competitiva perante os concorrentes e possui estratégias com vistas a alcançar a sustentabilidade demonstrada no Planejamento Estratégico Empresarialassociada aos objetivos e metas.

A preocupação com a gestão sustentável também se comprova quando existem indicadores associados a todas as dimensões da sustentabilidade, distribuídos de modo uniforme, tanto na dimensão econômica, como na social e ambiental.

A sistematização proposta, e descrita anteriormente, parte do princípio que existe PEE elaborado, indicando fragilidade caso esse processo não tenha sido realizado. No entanto, a utilização dos conceitos de IOC e de Big Data de modo sistematizado como foi proposto nesse trabalho, pode auxiliar o desenvolvimento e a criação do Plano Estratégico Empresarial no momento que são analisadas ameaças e oportunidades, forças e fraquezas e são estabelecidos os objetivos e as metas a serem alcançadas, demonstrando ao final da elaboração do plano, a preocupação da instituição também com as questões ambientais e sociais. Nesse sentido, no experimento apresentado no trabalho, diante da evidente preocupação da organização em estudo com as questões econômicas, permitiu a empresa refletir e rever o PEE, equilibrando os objetivos, metas e indicadores nas três dimensões da sustentabilidade. Associado a isso, diante dos indicadores valorados, outra reflexão possível é avaliar se as estratégias a serem seguidas para alcançar os objetivos e as metas estão adequadas.

\section{Referências}

ALVES, Robson de Paula; FALSARELLA, O. M. Modelo conceitual de inteligência organizacional aplicada à função manutenção. Gestão e Produção, São Carlos, v. 16, n. 2, p. 313-324, abr.-jun. 2009.

AMARAL, Sérgio Pinto, Emílio Lèbre, Estabelecimento de indicadores e modelo e relatório de sustentabilidade ambiental, social e econômica: uma proposta para a indústria de petróleo brasileira. 2003.

250f.Tese(Doutorado) - COPPE/UFRJ, Rio de janeiro, 2003.

ARAUJ O, Geraldino Carneiro de; BUENO, Miriam Pinheiro; SOUZA, Adriana Alvarenga de; MENDONÇA, Paulo Sérgio Miranda, Sustentabilidade empresarial, conceito e indicadores. CONVIBRA, 3., 2006, p.1-20. 
AGARWAL, Puneet; SHROFF, Gautamand; MALHOTRA, Pankaj. Approximate Incremental Big-Data Harmonization. IEEE INTERNATI ONAL CONGRESS ON BIG DATA, 2013. Santa Clara (CA), IEE Computer Society, 2013.

BARBIERE, J.C.; SIMANTOB, M. Organizações I novadoras Sustentáveis: uma reflexão sobre o futuro das organizações. São Paulo: Atlas, 2007.

BARBIERE, J. C.; VASCONCELOS, Isabella F. G. de; ANDREASSI, Tales; VASCONCELOS, F. C. de Inovação e sustentabilidade: novos modelos e proposições. RAE, São Paulo, v. 50, n. 2, p. 146-154, abr.-jun., 2010.

BEGOLI, Edmon; HOREY, James. Design Principles for Effective Knowledge Discovery from Big Data. In: J OINT WORKING CONFERENCE ON SOFTWARE ARCHITECTURE \& 6TH EUROPEAN CONFERENCE ON SOFTWARE ARCHITECTURE, IEEE Computer Society, 2012. p. 215-218.

BELLEN, Hans Michael Van. Indicadores de sustentabilidade - um levantamento dos principais sistemas de avaliação. CADERNOSEBAPE.BR, V. 2, n. 1, p. 1-14,mar. 2004.

BEULKE, Dave.Big Data Impacts Data Management: The 5Vsof Big, 2011. Disponível em: http://davebeulke.com/big-data-impacts-datamanagement-the-five-vs-of-big-data/. Acesso em: 15 jul. 2014.

BORELLI, Elizabeth; SILVA, Debora de Carvalho, Sistema de sustentabilidade empresarial como instrumento de gestão. In: SINGEP, 3/S2IS, 2, 2014, São Paulo. Anais[...], 2014, p.1-16.

BORKAR, Vinayak R.; CAREY, Michael J. and LI, Chen.Big Data Platforms: What's Next? XRDS, Fall, v. 19, n. 1, 2012.

CALLADO, Aldo Leonardo Cunha, Modelo de mensuração de sustentabilidade empresarial: uma aplicação em vinícolas localizadas na serra gaúcha, 2010, 216f. Tese (Programa de Pós-graduação em Agronegócio) - UFRGS, 2010.

CASARRO, A.C. Sistemas de informações para tomada de decisões. São Paulo: Pioneira Thomson Learning, 2010.

CLARO, Priscila Borin de Oliveira; CLARO, Danny Pimentel; AMÃNCIO, Robson, Entendendo o conceito de sustentabilidade nas organizações, R. Adm., São Paulo, v.43, n.4, p.289-300, out./nov./dez. 2008.

CORAL, Elisa. Modelo de planejamento estratégico para a sustentabilidadeempresarial. 2002. 282f. Tese (Doutorado em Engenharia 
da Produção). Universidade Federal de Santa Catarina, Florianópolis - SC, 2002.

FALSARELLA, O. M.; BERAQUET, V. S. M.; J ANNUZZI, C. A. S.

C.Informação empresarial: dos sistemas transacionais à latência zero. In: BERAQUET, V.S.M.; CIOL, R. (Orgs.). O profissional da informação na gestão - uma coletânea. Campinas: Akademika, 2010, v.1, p. 31-54.

FALSARELLA, O. M.; JANNUZZI, Celeste Aída Sirotheau

Corrêa ; BERAQUET, Vera Sílvia Marão . Informação empresarial: dos sistemas transacionais à latência zero. Transinformação, Campinas, v. 15, n.3, p. 141-156, 2003.

FALSARELLA, Orandi Mina ; J ANNUZZI, Celeste Aída Sirotheau Corrêa; SUGAHARA, C. R. Planejamento estratégico empresarial: Proposta de um sistema de inteligência organizacional e competitiva. Revista Digital de Biblioteconomia e Ciência da Informação, v. 12, p. 193-216, 2014.

FALSARELLA, Orandi Mina; JANNUZZI , Celeste Aída Sirotheau Corrêa ; SUGAHARA, Cibele Roberta. Gestão estratégica empresarial: proposição de um modelo de monitoramento informacional na era do big data. Revista Digital de Biblioteconomia e Ciência da Informação, v. 15, n. 2, p. 420-441, 2017.

FURTADO, João Salvador, Sustentabilidade empresarial: guia de práticas econômicas, ambientais e Sociais, Salvador: NEAMA/ CRA, 2005, 177 p. GUIMARÃES, Roberto Pereira; FEIXAS, Susana A. Q., Desafios na construção de indicadores de sustentabilidade. Ambiente \& Sociedade, Campinas, v.12, n. 2, p. 307-323, 2009.

HAM, Xiaoyue; TIAN, Lianhua; YOON, Minjoo; LEE, Minsoo, A Big Data Model supporting I nformation Recommendation in Social Network. In: International Conference on Cloud and Green Computing, IEEE computer society, 2012, p. 810-813.

JANNUZZI, Celeste Aída Sirotheau Corrêa; Falsarella, Orandi Mina; SUGAHARA, C. R. Sistema de informação: um entendimento conceitual para a sua aplicação nas organizações empresariais. Perspectivas em Ciência da Informação (Online), Belo Horizonte, v. 14, n. 4, p. 94-117, out./ dez. 2014.

JI, Changqing; LI, Yu; QIU, Wenming; AWADA, Uchechukwu; LI, Keqiu; Big Data Processing in Cloud Computing Environments. In: INTERNATIONAL SYMPOSIUM ON PERVASIVE SYSTEMS, ALGORITHMS AND NETWORKS, 2012, San Marcos. p. 17-23. 
KAISLER, Steve; ARMOUR, Frank; ESPINOSA, Albert.Introduction to Big Data: Scalable Representation and Analytics for Data Science. In: I NTERNATIONAL CONFERENCE ON SYSTEM SCIENCES, 46, 2013, Hawai. IEEE Computer Society, 2013. p. 984-984.

LAKATOS, E. M.; MARCONI, M. de A. Metodologia do trabalho científico. 7. ed. São Paulo: Atlas, 2007.

MARTINS, E. S.; ROSSETTO, C. R.; ROSSETTO, A. M.; FERREIRA, E.Estudo da sustentabilidade empresarial: o caso de uma cooperativa gaúcha. Revista Eletrônica de Gestão Organizacional, p. 457-482, set./ dez. 2010.

MERIAN, Lucas. World's data will grow by 50X in next decade, IDC study predicts. Computerworld, 28 jun. 2011.

https://www.computerworld.com/article/2509588/world-s-data-will-growby-50x-in-next-decade--idc-study-predicts.html. Acesso em: 28 fev. 2018.

MUNCK, Luciano; SOUZA, Rafael Borim de.Responsabilidade social empresarial e sustentabilidade organizacional: a hierarquização de caminhos estratégicos para o desenvolvimento sustentável. Revista Brasileira de Estratégia, Curitiba, v. 2, n. 2, p. 185-202, maio/ago. 2009.

MITHAS, Sunil; LEE, Maria R; EARLEY, MURUGESAN, Seth San and DJ AVANSHIR, Reza. Leveraging Big Data and Business Analytics IT. IEEE Computer Society, Nov./Dec., 2013.

NASCIMENTO, Elimar Pinheiro.Trajetória da sustentabilidade: do ambiental ao social, do social ao econômico. Estudos Avançados, v. 26, n. 74, p.51-64, 2012.

RIZZO, G. de A.; FALSARELLA, O. M. Estrutura Informacional para Monitoramento do Planejamento Estratégico Apoiado no Balance Scorecard. eGesta - Revista Eletrônica de Gestão de Negócios, v. 2, n. 2, p. 113-137, 2006.

SARAIVA, Luiz Alex Silva; CAMILO, Mário Carpegiane da Silva, Indicadores de desempenho em uma empresa industrial: concepção, uso e análise. FACEF PESQUISA, v.13, n.3, 2010.

SINGH, Sachchidan; SINGH, Nirmala. Big Data Analytics. In: INTERNATIONAL CONFERENCE ON COMMUNICATION, I NFORMATION \& COMPUTING TECHNOLOGY (ICCICT), 2012, Mumbai, I ndia, 2012. 